\title{
VALORISATION: THE CASE OF THE FACULTY OF APPLIED SCIENCES AT THE NATIONAL UNIVERSITY OF SCIENCE AND TECHNOLOGY, ZIMBABWE
}

\author{
S. Ngwenya* \\ Centre for Research on Evaluation, Science and Technology (CREST) \\ e-mail: ngwenyasimilo@gmail.com
}

\section{N. Boshoff*}

Centre for Research on Evaluation, Science and Technology (CREST) and DST-NRF Centre of Excellence in Scientometrics and Science, Technology and Innovation Policy (SciSTIP)

e-mail: scb@sun.ac.za

*Stellenbosch University

Stellenbosch, South Africa

\section{ABSTRACT}

Valorisation is a process that adds value to academic knowledge. It comprises all activities pertaining to the dissemination and exploitation of such knowledge for social and economic benefit. A 4D valorisation map was generated for the National University of Science and Technology (NUST) in Zimbabwe, and specifically for the Faculty of Applied Sciences. The first three dimensions of the map are constants: actor (university), level of aggregation (faculty) and discipline (applied sciences). Quantitative and qualitative indicators were presented in the fourth dimension (stage), using three data sources: semi-structured interviews, Scopus publications and university documents. Results were organised according to the six stages of the fourth dimension: formulation of mission and policy (stage 1), agenda setting (stage 2), execution of research (stage 3 ), dissemination of results (stage 4), uptake and use of research (stage 5) and other interaction throughout the entire process (stage 6). The resultant valorisation map for NUST incorporated more qualitative (and often anecdotal) evidence than quantitative evidence. The university should keep records of dissemination and engagement activities for future mapping exercises.

Keywords: knowledge, research, society, transfer, university, valorisation, Zimbabwe

\section{INTRODUCTION}

The need for universities to link with the world outside academe is a current and global phenomenon (Boshoff 2017; Enders and De Weert 2009). Universities are responding to this challenge in a variety of ways. For instance, in sub-Saharan Africa, 22 of the region's universities have embarked on a process of institutionalising research uptake management (RUM), mainly under the influence of the Development Research Uptake in Sub-Saharan 
Africa (DRUSSA) programme (DRUSSA 2016). Research uptake includes "all the activities that facilitate and contribute to the use of research evidence by policy-makers, practitioners and other development actors" (DFID 2016, 1). Based on this definition, RUM is viewed as a "new specialism in research management that addresses the coordination of activities concerned with the successful uptake of research evidence” (Grobbelaar and Harber 2016, 157).

This description of research uptake bears a strong resemblance to valorisation, which, in the Netherlands, is the legally prescribed "third mission" of universities, after education and research (Hladchenko 2016). As a process, valorisation is about adding value to knowledge, and includes any activity that relates to the dissemination and exploitation of knowledge for social and economic benefit (UvA 2014). The 4D valorisation model is a tool that was developed to create insight into the broad and multi-faceted process of valorisation (Van Drooge et al. 2013).

The current study was the first known attempt to apply the $4 \mathrm{D}$ valorisation model to a developing country institution, namely the National University of Science and Technology (NUST) in Zimbabwe, and specifically the university’s Faculty of Applied Sciences (FAS). Three objectives directed the study: firstly, to investigate how valorisation is embedded in the practices of FAS at NUST; secondly, to highlight the relevant indicators of valorisation and, thirdly, to reflect on the availability of data for such indicators.

Before addressing these objectives, the notion of valorisation and the $4 \mathrm{D}$ valorisation model are discussed in detail. A brief discussion of university research in Zimbabwe, and specifically at NUST, is also provided.

\section{VALORISATION AND THE 4D VALORISATION MODEL}

Valorisation, as a process, can be interpreted in two ways. On the one hand, it refers to the process of making academic knowledge "suitable or available for economic or social exploitation" (UvA 2014, 4). On the other hand, it refers to the "exploitation of such knowledge through competitive products, services, processes and new activities” (UvA 2014, 4). Academic knowledge is made available to others through knowledge dissemination, which involves any activity whereby academic knowledge is made public for use by people or organisations. Knowledge dissemination manifests in different ways, for instance, through a researcher's participation in a national working group responsible for developing public policy. Knowledge exploitation also follows different trajectories. A typical trajectory is contract research, where third parties have a direct interest in the university research and are therefore paying for it and eventually also acting upon its results (UvA 2014).

From the above, it can be gleaned that valorisation, from the perspective of scientific 
knowledge production, encompasses -

"all activities that contribute to ensuring that the outcomes of scientific knowledge add value beyond the scientific domain. It includes making the results from academic research available or more easily accessible in order to increase the chances of others - outside academia - making use of it, as well as the co-production of knowledge with non-academic groups” (Benneworth and Jongbloed 2010, 567-568).

According to Van Drooge and De Jong (2015), definitions of valorisation typically share four features: (1) a process that (2) applies to any discipline and which (3) takes on different forms and manifestations, with the aim to (4) enhance societal impact in the broadest sense of the word. These features also informed the development of the 4D valorisation model (Van Drooge et al. 2013), which is the focus in the current study.

The relevant model highlights four dimensions of valorisation, hence the name "4D" (Table 1). Together the four dimensions allow for specific cases (e.g. a university research group or a university faculty) to be "mapped" in terms of its valorisation potential and manifestation, through relevant indicators. The 4D valorisation map uses indicators in a generic sense to imply both quantitative and qualitative indications (i.e. figures and descriptions).

Table 1: The four dimensions of the 4D valorisation model

\begin{tabular}{|c|c|}
\hline Dimensions & Descriptions \\
\hline Actor & $\begin{array}{l}\text { Three categories of actors are responsible for valorisation: } \\
\text { - the knowledge provider (e.g. a research institute or university) } \\
\text { - the knowledge user (e.g. a company or a social group) } \\
\text { - the intermediary (e.g. a science granting council) }\end{array}$ \\
\hline Level of aggregation & $\begin{array}{l}\text { The responsibility for valorisation is held at different levels: } \\
\text { - the institutional level (e.g. of the university, company or science granting council) } \\
\text { - the mid-level (e.g. departments or programmes) } \\
\text { - the practical level (e.g. researchers or projects) }\end{array}$ \\
\hline Discipline & Valorisation applies to all disciplines and research fields. \\
\hline Stage & $\begin{array}{l}\text { Valorisation applies to all stages of research: } \\
\text { - formulation of mission and policy } \\
\text { - agenda setting } \\
\text { - execution of research } \\
\text { - dissemination of results } \\
\text { - application and use of research } \\
\text { - other interaction throughout the entire process }\end{array}$ \\
\hline
\end{tabular}

Source: Compiled from Van Drooge et al. $(2013,18)$

The first three dimensions reflected in Table 1 are predefined when constructing a valorisation map. In the current study, the three "constants” were: university (actor), faculty (mid-level aggregation) and applied sciences (discipline or rather a set of disciplines). The fourth dimension (stage) presents the indicators that are unique to each case, incorporating both quantitative and qualitative data. When developing a valorisation map, it is imperative to reflect on the characteristics of the case under study (Van Drooge et al. 2013). Relevant questions for 
reflection include the following: What does the actor (or faculty in this case) want to achieve in terms of valorisation? What is the faculty's responsibility? What is the faculty's influence? What goals are set to realise the mission of the faculty? What strategies are implemented to ensure that the goals are achieved? How does the faculty organise its research? With whom does the faculty cooperate and why? And how does the faculty make its research known?

FAS was selected for a valorisation map because of its relatively more research activity compared to the other faculties at the university (NUST 2016c). It was also believed that FAS would be associated with clear instances of valorisation, based on the assumption that research in the applied sciences is oriented towards developing practical solutions for real-life problems.

\section{CONTEXT OF UNIVERSITY RESEARCH IN ZIMBABWE AND AT NUST}

In Zimbabwe, the office of the president and cabinet is responsible for the formulation, review and approval of research policy as well as for its implementation (OPC 2017). The Ministry of Higher and Tertiary Education is located in that office and looks after 16 universities (ten statefunded and six privately owned). These universities are at different stages of development. The University of Zimbabwe, established in 1952, is the oldest and largest. NUST, which was established in 1991, is the second largest. Teaching and learning had always been a strong focus of Zimbabwean universities (57\% concentration), followed by research (28\%) and community service (15\%) (Pasipamire 2015). Pasipamire further remarks that an increased focus on research is becoming evident, thereby creating an environment in which research and teaching activities are demanding equal attention.

Between 2000 and 2008, the country faced a number of challenges, which affected its research activities. During this period, the country went through hyperinflation, the economy almost collapsed, and a massive humanitarian crisis emerged, which led to a third of the population migrating to nearby countries (Cross 2016). According to the Scientific Industrial Research and Development Centre (SIRDC 2003), Zimbabwe's expenditure on research and development (R\&D), at the turn of the century, was only about 0.2 per cent of the country's gross national product. Considering the financial challenges that the country faced and is still facing, informal funding from international funding agencies and project collaborations accounts for most of the country's R\&D activities. Retention of qualified senior staff presents a major challenge as most graduates sent for training abroad never return (Chinamasa 2012). Mouton et al. (2008, 250) describe the human capital base in Zimbabwe (at the time of the economic meltdown) as having "been eroded to the point where effective research and teaching is barely possible".

In 2006, the Ministry for Tertiary and Higher Education set out goals to address 
Zimbabwe's multiple challenges in the higher education sector. Some of the goals included "enhancing quality education and relevance of higher and tertiary education" as well as ensuring that institutions "link the programmes they offer to the economic and developmental needs of the country" (Mawoyo 2012, 117-118). To this end, universities are now striving to produce learners and research that directly address societal challenges. NUST, for instance, aspires to be an International Centre of Excellence in Science and Technology and Entrepreneurship for Sustainable Development by 2025 (NUST 2017a).

The Research and Innovation Office (RIO) at NUST is fostering a culture of collaborative and innovative research at the institution. For instance, in terms of research support, academics can apply for a research grant (maximum US \$5 000), a small block allocation for research (maximum US \$210) and a travel grant (maximum US \$2 500) (NUST 2011a). Despite these positive initiatives, some perception of instability of research funding still exists. This, together with potential political sensitivity surrounding certain research findings, constrains research by academics and their involvement in public engagement (Ndlovu, Joubert and Boshoff 2016).

It is against this background that a 4D valorisation map for FAS at NUST should be viewed. FAS is composed of nine departments: Applied Biology and Biochemistry (DABB), Applied Chemistry (DAC), Applied Physics (DAP), Applied Mathematics (DAM), Computer Science (DCS), Statistics and Operations Research (DSOR), Environmental Science and Health (DESH), Forest Resources and Wildlife Management (DFRWM), and Sports Science and Coaching (DSSC). All departments offer both undergraduate and postgraduate degree programmes. In 2015, the faculty had 127 academic staff (NUST 2016c).

\section{METHODOLOGY}

A draft outline of a valorisation map for FAS was compiled by modifying an existing example for a humanities faculty (Van Drooge et al. 2013, 24-25). This was followed by empirical work to generate the information needed to "populate" the indicator categories presented in the fourth dimension of the 4D map. The empirical work comprised the screening of relevant university documents, a bibliometric analysis and semi-structured interviews with university representatives.

The bibliometric analysis involved an analysis of publications published between 2005 and 2015, and which were indexed by Scopus. Specifically, all Scopus publications with at least one author affiliated to Zimbabwe were identified and exported to a Microsoft Access database. This generated 3856 publications. Publications with at least one author address affiliated to NUST were also identified to produce a dataset of 234 NUST publications (including 176 FAS publications). Each of the 234 publications was described in terms of five data elements: unique 
identification number, year of publication, title of publication, source of publication, and document type. The relevant document types were: articles (201), review articles (2), conference papers (18), book chapters (11), books (1) and editorials (1). New variables indicating different forms of collaboration (e.g. international versus national collaboration) were also created in the NUST dataset.

In October 2016, semi-structured (face-to-face) interviews were conducted with 10 university representatives: the dean of FAS and the chairpersons of all nine departments. The reason for their selection was because of an informed understanding of faculty processes and activities. On average, an interview lasted about thirty minutes, and notes were taken down. The questions focussed on four themes: the societal and economic mission of the faculty or department, instances of the uptake of research at the faculty or department, potential stakeholders and beneficiaries of research, and relevant research engagements of academic staff members in the faculty or department.

Relevant university documents consulted included the following: the latest annual report of the vice-chancellor (NUST 2016c), the draft research policy (NUST 2013), the intellectual property policy (NUST 2007), the procedures and guidelines for research applications (NUST 2011a), and the university's yearbook (NUST 2011b). The university's repository was consulted (on 5 October 2016) for the number of theses produced by FAS students, and the faculty and departmental websites for information on mission statements (on 5 October 2016 and 6 June 2017).

\section{RESULTS}

The results are presented in terms of the six stages of the fourth dimension of the 4D valorisation model. Although these valorisation stages overlap with those of the research process (specifically research execution, dissemination and use), it should be remembered that the process of valorisation is much broader than the research process. Valorisation encompasses all arrangements and activities that add value to academic knowledge (which includes knowledge produced by the research process) in order to create societal and economic benefit.

\section{Stage 1: Formulation of mission and policy}

Ideally, valorisation mapping should first establish what the entity under investigation wants to achieve in terms of valorisation. This section therefore highlights the societal and economic mission of NUST. Also included are relevant institutional policies and guidelines that support the societal and economic mission of the institution. The following statement captures the broad mission of FAS: 
To contribute positively towards the advancement of science for community development, through the provision of knowledge based solutions to scientific, technological, economic and social challenges (NUST 2016a).

All nine departments have mission statements that, to various degrees, make explicit reference to contributing to the well-being of society and addressing the needs of industry and other specific stakeholders (Table 2 - version of 6 June 2017). However, eight months earlier these statements looked different. At that time, only five departments (DABB, DAC, DCS, DSOR and DSSC) included an explicit reference to external stakeholders (Table 2 - version of 5 October 2016). Also, in the case of four departments, their mission statement was an exact copy of that of another department (DABB and DAC versus DESH and DFRWM), of which one statement focussed on the educational needs of undergraduate students only.

All 10 interviewees received a draft of the results of the 4D valorisation mapping exercise in early 2017. Subsequent changes to the mission statements may therefore be attributed to the mapping exercise and specifically to its value as a tool for organisational learning and improvement (Van Drooge et al. 2013).

Table 2: Mission statements of FAS departments

\begin{tabular}{|c|c|c|}
\hline \multicolumn{2}{|c|}{ Mission statements } & \multirow[t]{2}{*}{ Departments } \\
\hline As on 6 June 2017 & As on 5 October 2016 & \\
\hline $\begin{array}{l}\text { "To produce high-quality graduates who will be able to } \\
\text { use their knowledge towards the provision of } \\
\text { knowledge-based solutions to scientific and } \\
\text { technological problems and to contribute to industrial } \\
\text { development in the fields of Applied Biology and } \\
\text { Biochemistry" (NUST 2017b). }\end{array}$ & \multirow{2}{*}{$\begin{array}{l}\text { "To produce high-quality graduates } \\
\text { who will be able to use their } \\
\text { knowledge to the practical solutions of } \\
\text { real problems and to contribute to the } \\
\text { further development in the field of } \\
\text { [Applied Biology and Biochemistry, or } \\
\text { Applied Chemistry], meeting the } \\
\text { requirements and challenges of the } \\
\text { competitive job market" (NUST } \\
2017 b, 2017 \mathrm{c} \text { ). }\end{array}$} & DABB \\
\hline $\begin{array}{l}\text { "To advance and apply knowledge through research, } \\
\text { innovation and creativity across all fields of Chemistry } \\
\text { for a positive impact on the quality of life and the } \\
\text { economy of Zimbabwe and the world at large" (NUST } \\
\text { 2017c). }\end{array}$ & & DAC \\
\hline $\begin{array}{l}\text { "To contribute to the teaching of Applied Mathematics, } \\
\text { research and community engagement" (NUST } \\
\text { 2017d). }\end{array}$ & $\begin{array}{l}\text { "To contribute to the teaching of } \\
\text { Applied Mathematics, research and } \\
\text { community engagement" (NUST } \\
\text { 2017d). }\end{array}$ & DAM \\
\hline $\begin{array}{l}\text { "To achieve self-reliance and competitiveness through } \\
\text { high-quality training and research fostering creativity } \\
\text { and innovation in designing high-quality scientific } \\
\text { products used in modern laboratories, hospitals, } \\
\text { industries and society at large" (NUST 2017e). }\end{array}$ & $\begin{array}{l}\text { "To produce physicists who have } \\
\text { acquired skills and knowledge that } \\
\text { enable them to analyse problems in } \\
\text { mathematical terms and familiarise } \\
\text { themselves with sophisticated } \\
\text { experimental equipment" (NUST } \\
2017 \text { ). }\end{array}$ & DAP \\
\hline $\begin{array}{l}\text { "The realisation of excellence and highest quality in } \\
\text { applying the rigorous competence-based training, } \\
\text { teaching research and development to identify and } \\
\text { meet the dynamic information and communication } \\
\text { technology (ICT) manpower needs of industry and } \\
\text { commerce" (NUST 2017f). }\end{array}$ & $\begin{array}{l}\text { "The realisation of excellence and } \\
\text { highest quality in applying the } \\
\text { rigorous competence-based training, } \\
\text { teaching research and development } \\
\text { to identify and meet the dynamic } \\
\text { information and communication } \\
\text { technology (ICT) manpower needs of } \\
\text { industry and commerce" (NUST } \\
2017 \text { ). }\end{array}$ & DCS \\
\hline
\end{tabular}




\begin{tabular}{|c|c|c|}
\hline \multicolumn{2}{|c|}{ Mission statements } & Departments \\
\hline As on 6 June 2017 & As on 5 October 2016 & \\
\hline $\begin{array}{l}\text { "To contribute positively in community lives } \\
\text { enhancement through environmental protection" } \\
\text { (NUST 2017g). }\end{array}$ & \multirow{2}{*}{$\begin{array}{l}\text { "To provide broad-based education } \\
\text { for undergraduate students in the field } \\
\text { of [Environmental Science and } \\
\text { Health, or Forest Resources and } \\
\text { Wildlife Management]" (NUST } 2017 \mathrm{~g} \text {, } \\
2017 \mathrm{~h} \text { ). }\end{array}$} & DESH \\
\hline $\begin{array}{l}\text { "To produce graduates who are knowledgeable and } \\
\text { passionate about forestry and wildlife matters, in } \\
\text { Zimbabwe, in Africa and globally. The research } \\
\text { conducted by the department will contribute } \\
\text { meaningfully to the sustainable development of } \\
\text { Zimbabwe" (NUST 2017h). }\end{array}$ & & DFRWM \\
\hline $\begin{array}{l}\text { "To provide a solid foundation in quantitative analysis } \\
\text { and business decision analysis to our students and } \\
\text { other stakeholders, by providing excellence in } \\
\text { teaching, research and community service" (NUST } \\
\text { 2017j). }\end{array}$ & $\begin{array}{l}\text { "To provide a solid foundation in } \\
\text { quantitative analysis and business } \\
\text { decision analysis to students and } \\
\text { other stakeholders, by providing } \\
\text { excellence in teaching, research and } \\
\text { community service" (NUST 2017j). }\end{array}$ & DSOR \\
\hline $\begin{array}{l}\text { "To produce innovative and enterprising graduates } \\
\text { with appropriate knowledge, skills and attitudes to } \\
\text { contribute adequately to both general and elite } \\
\text { sporting needs of the country" (NUST 2017i). }\end{array}$ & $\begin{array}{l}\text { "To produce innovative and } \\
\text { enterprising graduates with } \\
\text { appropriate knowledge, skills and } \\
\text { attitudes to contribute adequately to } \\
\text { both the general and elite sporting } \\
\text { needs of the country" (NUST 2017i). }\end{array}$ & DSSC \\
\hline
\end{tabular}

A number of policies, strategies and guidelines at NUST support the faculty's broad mission of providing "knowledge based solutions to scientific, technological, economic and social challenges” (NUST 2016a). For instance, the NUST intellectual property policy (NUST 2007) aims to -

"foster an enabling environment that encourages the generation of and expedites the dissemination as well as application of new knowledge by researchers at NUST for the benefit of the public through efficient processes of technology transfer" (NUST 2007, 1).

Similarly, the university’s draft research policy (NUST 2013) also supports the societal and economic mission of FAS. The policy encourages "research that is relevant to the needs of all communities (locally, regionally and internationally)” (NUST 2013, 1), and emphasises that research should be communicated to potential users and beneficiaries. By stating that socially relevant research should be based on good research practices and high-quality science, the policy also echoes the view that outstanding science is needed for valorisation to be credible and of high quality (ECV 2013) -

"Good research practice underpins high quality science and supports robust evidence needed to drive improvements and solve problems faced by the society. Good research practice also helps to increase public confidence and trust in the research process and its outputs” (NUST 2013, 1).

Certain aspects of the NUST Research Board Procedures and Guidelines for Applicants (NUST 2011a) also speak to the valorisation process. For instance, when assessing applications for 
university research grants, the research board gives due weight to proposals that have direct relevance to Zimbabwean circumstances. However, considerations of societal relevance do not occur at the expense of expanding scientific knowledge. For instance, the assessment criteria also include determining whether the proposed research exhibits originality in the discovery of new facts. FAS regularly accesses the bulk of the budget dispersed under research grants (e.g. $50 \%$ in 2015 [NUST 2016c]).

Academics can also apply for travel grants, both within and outside Zimbabwe (NUST 2011a), where such grants are typically used for research field trips, visits to other organisations and conference attendances. In 2015, FAS accessed 36 per cent of the total budget disbursed under travel grants (NUST 2016c). However, an academic who receives the maximum allowance of US \$2 500 must wait for two years before becoming eligible for a travel grant again. According to the interviewees, this stipulation restricts their continued access to the fund and therefore also affects the valorisation process to a certain degree.

\section{Stage 2: Agenda setting}

This section highlights two aspects of agenda setting as outlined in the 4D valorisation model: strategic collaborative engagements with external stakeholders and instances of participation in research initiatives. The interviewees were therefore asked whether they had any strategic collaborative engagements and to explain the origin and nature of those. Please note, all quotations are reflected verbatim and unedited.

The interviews revealed that the bulk of the strategic collaborative engagements of the faculty stemmed from industry where bachelor students go for industrial attachment. It is compulsory for undergraduate students to go for industrial attachment in the third year of a four-year bachelor's programme (NUST 2011b, 111). Industrial attachment provides an opportunity for theory learnt at university to be applied to actual problems in industry.

Each FAS department has an industry advisory board, which is composed of both industry representatives and designated departmental staff. One reason for having these boards, according to the DAM representative, is to deliver students “relevant to industry”. Engagements with industry at board meetings keep departments informed about the latest industry developments and help them to rebrand their academic offerings accordingly.

Funding bodies also facilitated the relationships some departments had with societal stakeholders. For instance, the DAP respondent stated, “After receiving funding to carry out a research project on underground water from the International Science Programme, we were prompted to engage the Bulawayo City Council in Zimbabwe”. In some other cases, research exhibitions by academic staff members at fairs resulted in university-industry relationships 
being established. The representative of the DCS provided an example: "After exhibiting our research work at the Zimbabwe International Trade Fair, we were approached for collaborative research by two telecommunications companies in Zimbabwe”. The provision of research facilities by external parties also instigated new relationships in some cases. According to the DFRWM representative, "Parks and Wildlife is our major stakeholder. We use their estates for our practical courses”. Asked about the nature of the faculty's engagements, the dean responded:

"Relationships are about research and teaching. Industry advisory boards advise departments during curriculum changes and 'part three' students [students in the third year of a four-year bachelor's programme] on industrial attachment identify problems in industry and come up with research that solves those issues. Relationships are also about community work.”

Examples were given of where relationships with stakeholders concerned research. According to the representative of DAM, the nature of the department's relationship with the local cotton industry was about "sharing of research and providing mathematical skills and analysis". The DAP representative also mentioned that their department's relationship with an international organisation in energy was mainly about research.

Interactions with stakeholders also included community oriented work. The DAM representative raised an example of the NUST Schools Enrichment Programme (NUST SEP). Operations started in 2010, with the main aim to address shortcomings associated with the low level of admission into the STEM (science, technology, engineering and mathematics) programmes at NUST. In 2013, four more departments (DAP, DABB, DAC and DSOR) became part of the programme by offering relevant subjects to underprivileged students.

In the case of the DSSC, according to its representative, the department regularly offers sport coaching to the Zimbabwe community. This is done jointly with three national bodies (Sports and Recreation Commission, Zimbabwe National Athletics Association and the Zimbabwe Olympic Committee). The DESH, on the other hand, represents NUST in the Africa Academy for Environmental Health and in the Stakeholders Forum on Urban Agriculture in Zimbabwe.

Lastly, the interviewees also mentioned that strategic collaborative engagements are often formalised through the signing of a memorandum of understanding (MoU).

\section{Stage 3: Execution of research}

This section highlights two aspects of research execution that shed light on the university's engagement in valorisation activities. The first is research through supervision, and specifically the decision about which research topics the supervised students should work on. The second 
aspect concerns the involvement of external parties in the research process as reflected by the nature of research collaboration.

Supervision of undergraduate and postgraduate students forms parts of the job description of all academics in the faculty, with the exception of teaching assistants. According to the dean, the students' research topics can have different origins: “Topics come from students. At times, research areas [that] are there in departments. Or companies have their own areas where they would want students on attachment to focus on”. Often departments encourage students to develop an own idea for research, as revealed by the DAC representative:

"We advise undergraduate students to think about 'my next big idea that will help change the world'. When students go to industry, they monitor how their big ideas come about. Their final year project has to do with their dream.”

A similar response was voiced by the representative of the DFRWM, "Students on industrial attachment identify problems in industry and they research on them". The same individual also recalled occasions where lecturers had provided undergraduate students with topics to pursue.

Figure 1 shows a breakdown of theses produced by the respective departments in FAS, in terms of level of qualification. The information was obtained from the university's institutional repository and the reference period is from 2005 to 2015.

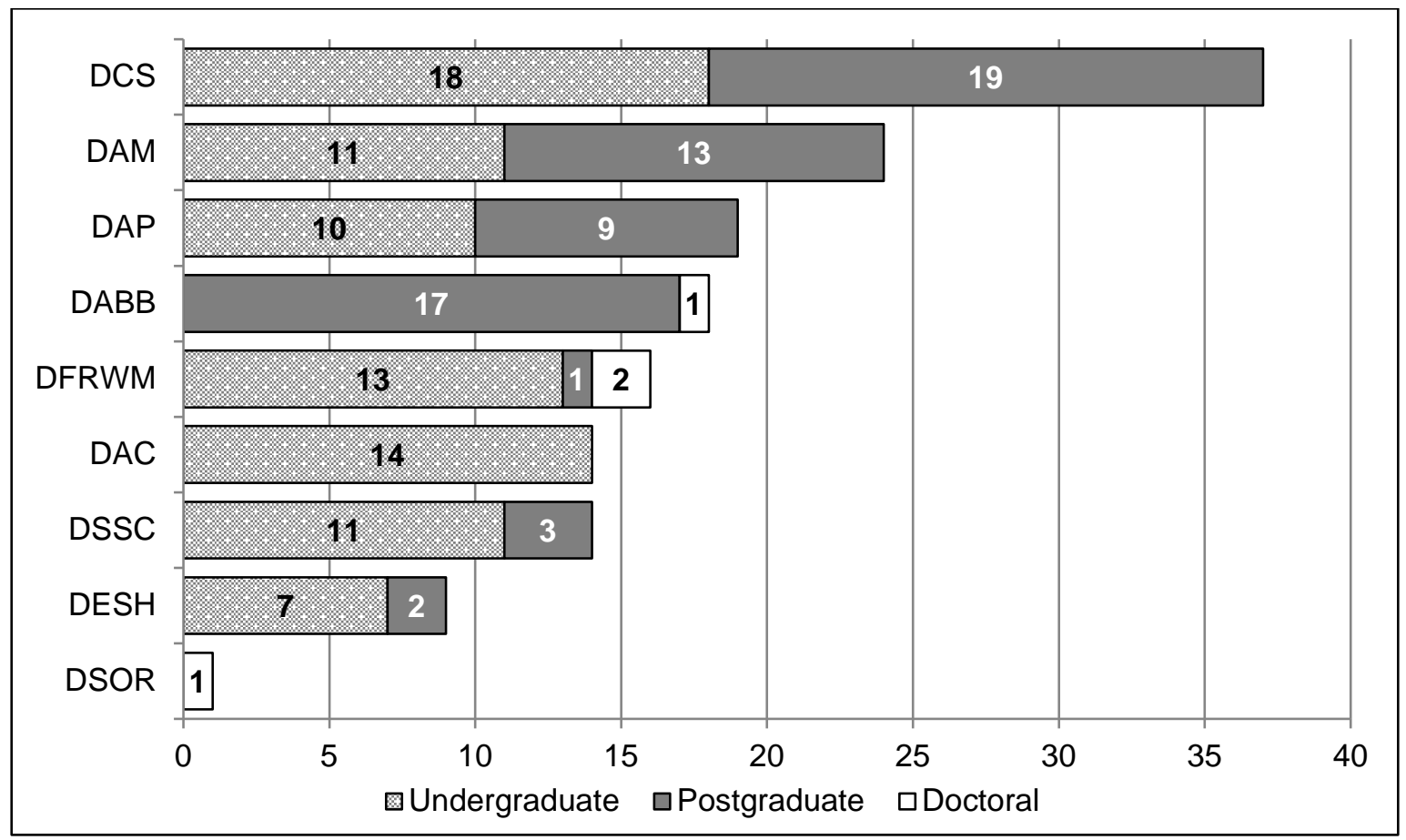

Note: The data source is the NUST institutional repository. "Postgraduate", in the terminology of the repository, refers to degrees such as MPhil and MSc.

Figure 1: Number of theses produced by FAS departments, 2005-2015, by level of qualification 
In Figure 1, undergraduate students account for the majority of projects (84) deposited at the NUST institutional repository. The DCS recorded the largest number of theses deposited at the repository.

The nature of research collaboration at FAS was assessed by analysing publication coauthorship, which is also the method used by Boshoff (2010) in a bibliometric study of research collaboration in southern Africa. The Scopus database recorded a total of 176 publications for FAS academics between 2005 and 2015. Figure 2 disaggregates these publications in terms of eight mutually exclusive categories. Almost two thirds (65\%) of FAS publications involved coauthorship with people outside NUST only, and 19 per cent with people in the same FAS department only.

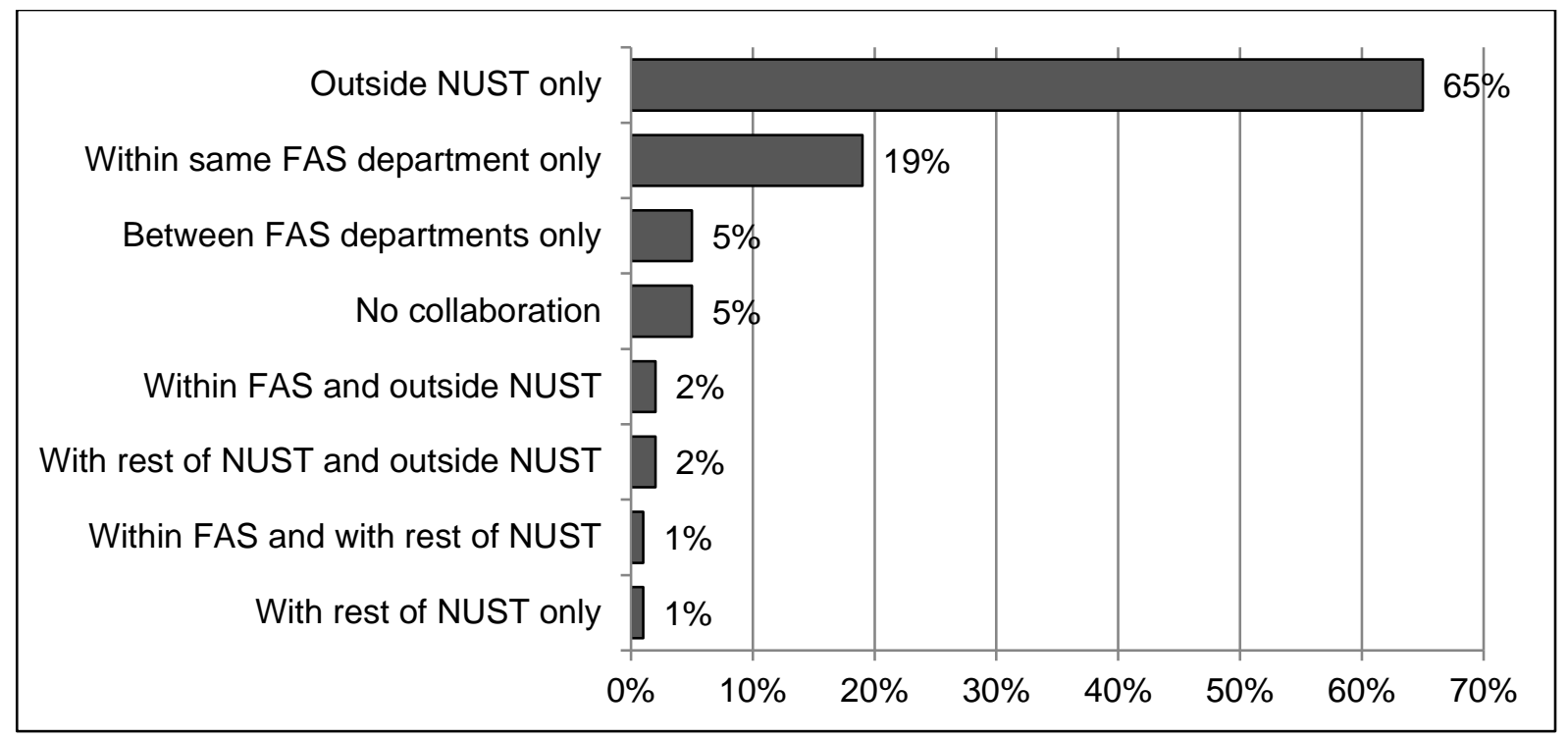

Figure 2: FAS publications in Scopus, broken down by nature of collaboration, 2005-2015 ( $n=176)$

Figure 3 gives a breakdown by sector of the 122 FAS publications that involved co-authorship with people outside NUST. Of these, 68 per cent were produced in collaboration with universities only. A steady increase in the share of publications co-authored with universities and other sectors is evident - from 12 per cent in the period 2005-2008 to 31 per cent in the period 2013-2015. One interpretation could be that the faculty is increasingly realising the importance of engaging other sectors in its research activities. 


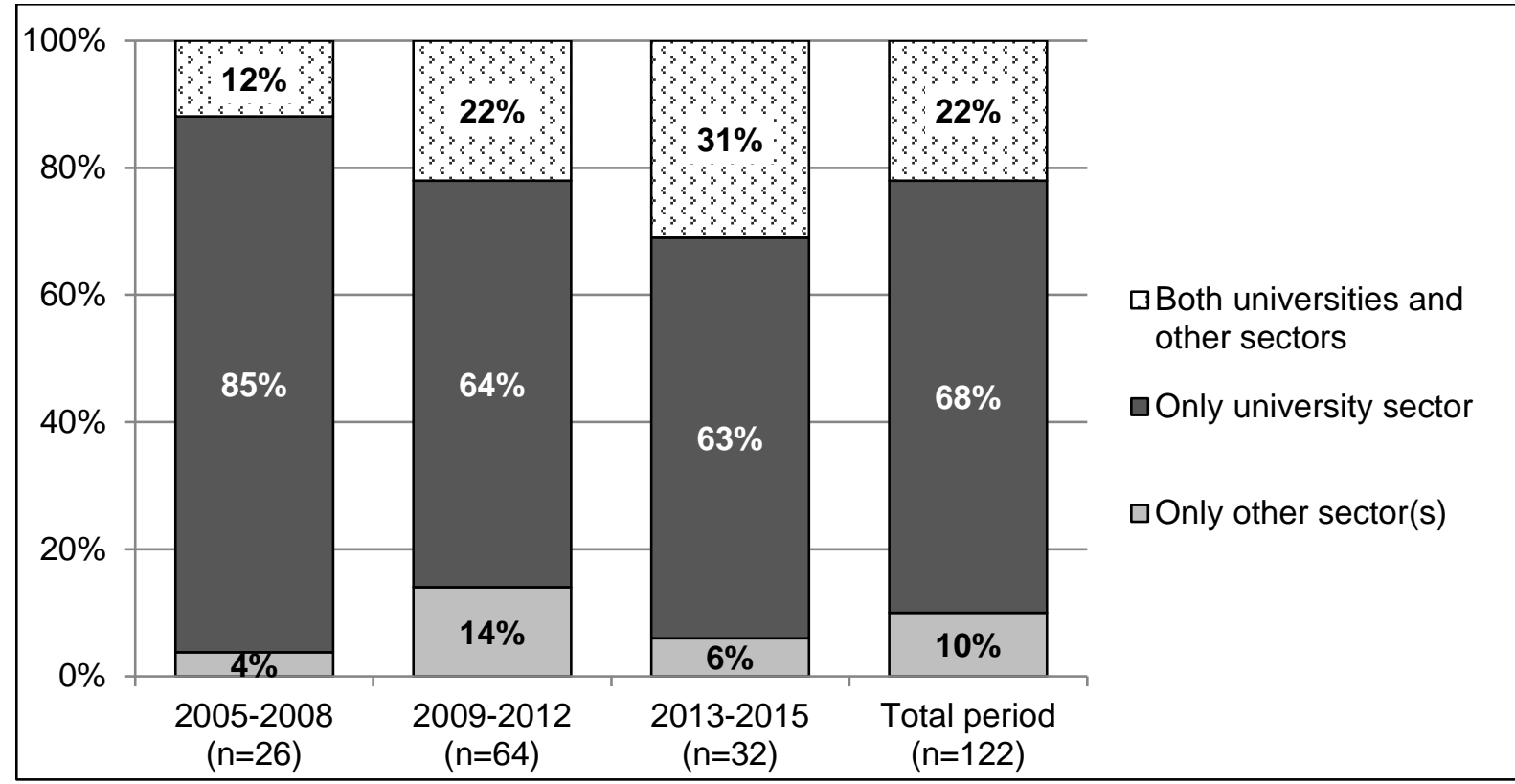

Figure 3: Sector breakdown of FAS publications that involve co-authorship outside NUST by year period

Figure 4 presents a breakdown of the faculty's 176 publications by national and international collaboration. Of these, two equally large percentages involved either only national collaboration (41\%) or only international collaboration (40\%). National collaboration was most prominent in the latest period (56\% in 2013-2015, which increases to 61\% if the overlap with international collaboration is included).

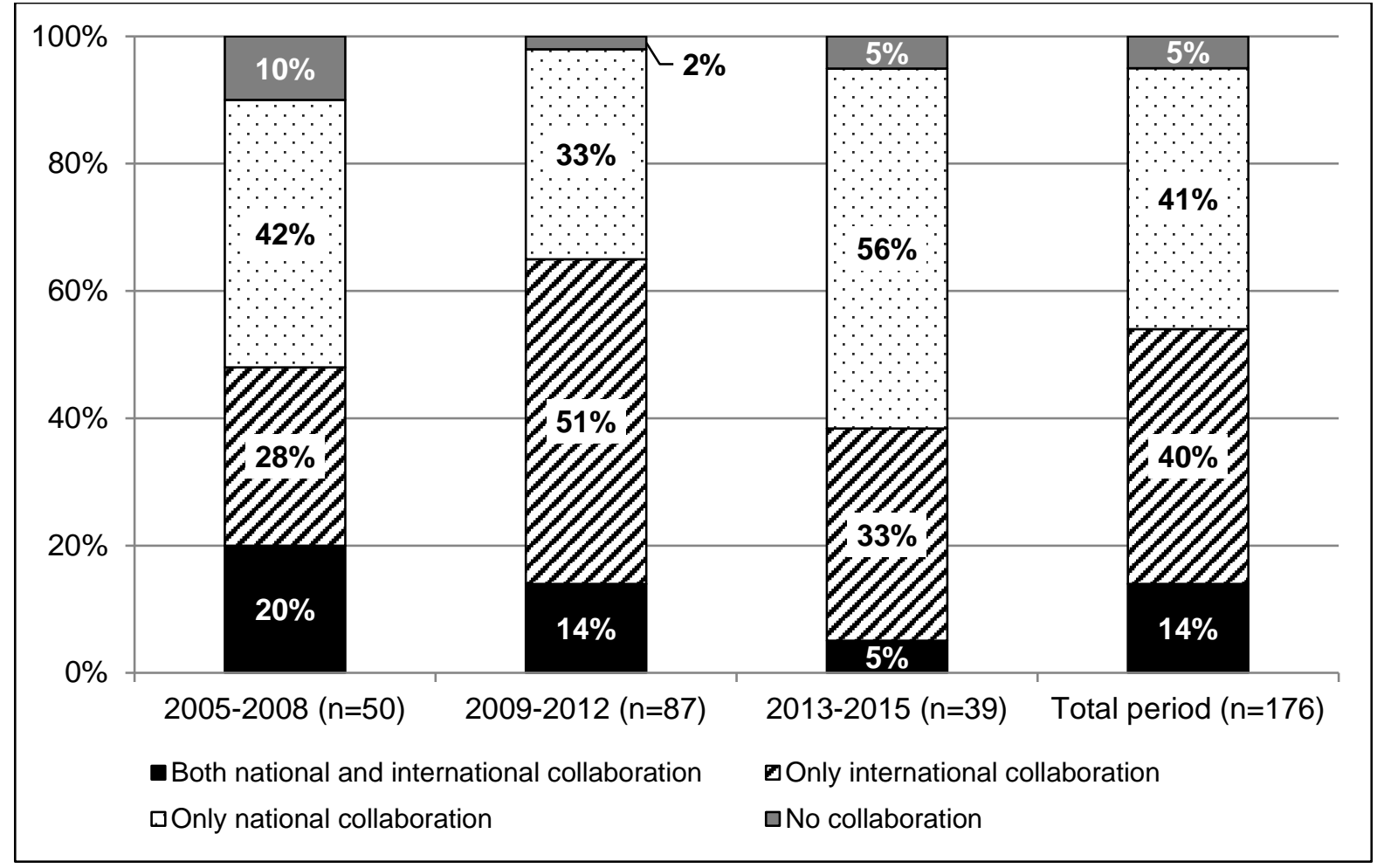

Figure 4: Breakdown of FAS publications in terms of national and international collaboration by year period 
The bibliometric analysis also revealed which Zimbabwean organisations collaborated in FAS publications. The two most frequently occurring organisations were the University of Zimbabwe (21 publications) and Lupane State University (8). FAS academics therefore share research interests with these two universities. The faculty also collaborated nationally with organisations other than universities. These included Border Timbers Limited (5 publications), which is a Zimbabwean company operating in the timber industry. Zimbabwean collaborators in the non-university sector also included the Zimbabwe Parks and Wildlife Management Authority (5 publications), CIRAD-Zimbabwe, which is a French international agricultural research institution for development in Zimbabwe (3), and the Central Veterinary Laboratories (3).

Three South African universities (University of Limpopo, Stellenbosch University and the University of Pretoria) each co-authored nine publications with FAS staff. Non-African universities also participated in co-authoring publications with FAS. These include the University of Guelph in Canada and Lund University in Sweden (7 and 4 publications respectively). Publications were also co-authored with other international entities. An example is the African Comprehensive HIV/AIDS Partnership in Botswana, which generated six publications. Still, the larger share of international FAS publications (53\% of 195) was coauthored with South Africa.

From the bibliometric findings, it therefore seems that FAS academics, in terms of research, mainly collaborate with individuals outside Zimbabwe. A possible explanation (also raised in the interviews) could be the fact that some faculty members were pursuing studies internationally. According to the representative of DAM, "Most academics in the department are studying abroad, and hence research collaborations are facilitated by them having a studentsupervisor relationship”. Participation at international conferences and seminars (see next section) could be another contributing factor to external collaboration.

\section{Stage 4: Dissemination of results}

The interviewees were asked about the audiences of their research and how they usually disseminate research findings to those audiences. They were also asked where their undergraduate and postgraduate students go to after degree completion. The question was considered relevant because knowledge travels with and is embodied in people (Boshoff 2014). The same reasoning also motivated a question about the involvement of the department in consultancy.

In the interviews, departments identified more or less the same research audiences. These ranged from government ministries to educational institutions, research centres, industry (such 
as manufacturing, mining and service), community members and students affiliated in the faculty. The interviews further highlighted that departments rely on a variety of media and platforms to disseminate their research results. These include publications, presentations and posters (at conferences, research seminars, annual research days, expos, fairs and exhibitions) and workshops. To these, the representative of DABB added, "We have a journal club which comprises of students and lecturers. Both students and staff members make research presentations in the club. The club helps students to develop their presentation skills.”

According to the annual report of the vice chancellor (NUST 2016c), FAS academics presented 52 papers at various conferences in 2015, of which 44 were presented at international conferences. The flagship national conference is RIO-SET (Research and Intellectual Outputs, Science, Engineering and Technology), which was initiated in 2011 by the ministry responsible for higher education and science and technology. It serves as a "platform from which Zimbabwe can harness and channel the knowledge" of the country's universities and research organisations together with that of "Zimbabweans in the diaspora", in order to achieve the country’s development goals (NUST 2016b). In 2015, FAS academics presented five papers at that year's RIO-SET. Also in 2015, the faculty presented ten papers at the annual NUST Research Day, an event that was first introduced in 2013 by the university's research office (NUST 2016c).

The evolving career path of the faculty's alumni also serves as a ready-made platform for research dissemination. However, the national uptake of university graduates is not ideal. Instead of working for local industry, the after-effects of the economic meltdown have compelled many graduates to seek employment and further training abroad. According to the representative of DAC, "Before economic meltdown, there was 100 per cent industry uptake, but currently, most of our students go to further their studies abroad and they do not come back". The few students who find employment in Zimbabwe are largely absorbed by government. The representative of DSOR echoed this, "Industries have closed and the government is now the largest employer”.

From the interviews it emerged that formal consultancy at NUST was not standard practice due to the university's procedures for registering a consultancy. For instance, all registrations must go through the technology transfer office at NUST, which levies its own taxes. Many academics therefore prefer their own (and much more informal) consultancies.

The interviewees also commented on the accessibility of their research to external parties. All perceived the research work done by the faculty as largely inaccessible. The representation of DFRWM commented, "Non-academic audiences are not really aware of our research”, while the DAC representative felt that "there is little interest among non-academics themselves". It 
was also mentioned that some companies do have policies in place that compel students to provide them with a copy of the research that was carried out at the company. The theses of FAS students were also believed to be accessible to potential users via the NUST institutional repository. However, not all student projects are deposited at the repository.

In order to make the university's research more accessible to outsiders, the representative of DABB suggested:

"We have to break down our research and make it easy to be understood by non-academic audiences. We have to publish our research work where non-academic audiences are. They obviously do not access open access resources but they read magazines and newspapers every day."

Asked how else research dissemination and uptake at NUST could be supported, the interviewee from DCS responded, “Academics need incentives and rewards for facilitating research uptake”.

\section{Stage 5: Uptake and use of research}

The interviewees reflected on what they consider possible instances of research uptake and use, and what would count as evidence of such occurrences.

The DFRWM participated in the formulation of national policy on Forest Management which is why, for that department's representative, “Instances of research uptake are seen when research is used to form part of policy”. Other instances are for instance that industry applies innovations emanating from FAS. The dean recalled, "An innovation by the Department of Applied Chemistry on water purification using a novel material [that] was taken up [by] one of the research members' community”.

For some interviewees, the uptake of research includes instances of academic staff being contacted by non-profit organisations and government bodies for seminars, consultancy or training. According to the representative of DABB, "After seeing one of our publications, Wildlife Trust Zimbabwe approached us for consultancy work”. The interviewee from the DCS recalled a similar set of events, “After seeing one of our ... student's project on a learning translator showcased at the Zimbabwe International Trade Fair, the Ministry of Primary and Secondary education approached us and requested that we develop a similar tool for Zimbabwe’s education”.

The referral of research results to government agencies, irrespective of what happens to the results after referral, also represents for some a form of research uptake. The interviewee from the DAM recalled an example: 
"We were tasked by Matopo Research Station to carry out randomised block designs where ostriches were fed with four different diets. The goal was to check which diets made ostriches gain weight faster. The results of this study were recommended to Zimbabwe National Foods. That counted as evidence that research uptake had occurred.”

For others, research uptake is inextricably linked to stakeholder meetings, workshops and seminars. According to the representative of DAP, "We held an indaba on underground water project with stakeholders and the Bulawayo community”. The representative of DFRWM conveyed a similar event, "We hold community training workshops on forestry and wildlife management and on climate change adaptation”.

With regard to spinning out new companies from research, the dean commented that foreign companies are usually contracted to do so, which is to the disadvantage of local companies, "Research and development is minimal. The manufacturing industry is not based in Zimbabwe. When opportunities for setting up new companies arise, local companies contact their head departments which are not in Zimbabwe."

Creating intellectual property (IP) at NUST and exploiting that IP, for instance, in spinoff companies, requires concrete measures. The DAC representative highlights the following:

\footnotetext{
"We need to develop a clear cut strategy on what exactly we want to achieve and on how we plan to achieve it. We have to go philanthropic and do pilot plans, and invite communities. We have to encourage NUST stakeholders to use NUST intellectual property rights to open their own business, where NUST will retain shares."
}

Finally, the interviewees also identified citations, a favourable h-index (i.e. an index used to quantify an individual scientist's cumulative research contribution - Hirsch 2005) and the registering of licenses and trademarks as evidence that research uptake has occurred.

\section{Stage 6: Other interaction throughout the entire process}

All interviewees reported that at least one academic staff member in their department had a working arrangement with or a dual appointment at another university. For instance, some DAB and DFWM staff also lectured at Lupane State University in Zimbabwe. In other departments (DAP, DAM and DCS), the interviewees provided examples of staff with dual appointments at South African universities. Other forms of inter-university interaction (both inside and outside Zimbabwe) included project supervision and the co-supervision of postgraduate students as well as external examining. 


\section{DISCUSSION}

Traditionally, assessments of the "impact" or "value” of an organisation's research activities have always been framed in terms of making some kind of judgement - i.e. arriving at a conclusion whether the desired outcome was achieved and, if so, how good that outcome was. Lately, however, a set of process-oriented approaches has surfaced in the assessment of research impact. The focus of these approaches is not on the long-term outcome (impact) of research but on the mechanisms and processes responsible for creating impact (Spaapen and Van Drooge 2011; Upton, Vallance and Goddard 2014). The 4D valorisation model is one such processoriented approach. The objective of valorisation mapping is therefore not to judge but to produce relevant insights that could inform organisational learning and action.

From the perspective of academics, though, especially at universities in Anglophone subSaharan Africa, there may be some objection to attempts to introduce the concept of valorisation and its institutionalisation. One objection could relate to the fact that the word "originated in Belgium and was first used in the Netherlands in the 2004 Netherlands Science Budget” and that it is also "seldom used outside the Netherlands and Belgium" (Van Drooge et al. 2013, 16). This means that valorisation - the term and the process - could be interpreted as essentially Eurocentric. For that reason, the term "research uptake" has a better chance of being embraced by African universities, especially since NUST, together with 21 other universities on the continent, participated in the DRUSSA programme that set in motion a process of institutionalising research uptake management (DRUSSA 2016).

A second possible objection to the institutionalisation of valorisation at African universities - and this equally applies to the institutionalisation of research uptake - is that it could be perceived as yet another challenge to African academics whose time and resources are thinly spread. However, as the current study has shown, the nine FAS departments already participated (to various degrees) in the different stages of valorisation. This supports the view of Van Drooge and De Jong (2015) that academics often do valorisation work without being aware that they are doing so. Effective valorisation is therefore not so much about taking on additional engagement activities. It is also about successfully managing relevant activities that are already happening and using the resultant insights to identify areas still in need of improvement.

Assessment tools, like the 4D valorisation model, are essential to manage the valorisation process properly. However, any assessment method is only as good as the indicators that it incorporates. In the current study, what did not come through clearly enough, was concrete quantitative evidence of valorisation. The few instances were limited to bibliometrics and to statistics from the vice-chancellors' annual reports. Hence, the current mapping had a strong 
focus on qualitative and often anecdotal evidence. For instance, stating that some theses originated with industry does not mean that it was in fact the case. Supporting evidence is required in the form of actual data (e.g. the number of theses produced in association with users). The lack of relevant quantitative data also prevented other indicators from being included - for instance, nothing is said about the number of reports produced in collaboration with users or based on questions put forward by users.

The point is, to manage the valorisation process (or the research uptake process for that matter) effectively, there should be appropriate records and databases to consult when constructing a 4D map. Universities are generally good with keeping record of institutional research activities but not so good, if at all, with keeping record of dissemination and engagement activities (Grobbelaar and Harber 2016). Ideally, there should be synergy between indicators representing three core elements: context, examples and numbers. This challenge needs to be addressed because valorisation mapping requires a good balance of both quantitative and qualitative indicators.

Collecting data for valorisation indicators might be easier said than done for universities in developing countries, given that many developing countries lack a culture of research evaluation. This is in direct contrast to some of the more developed economies of Europe where university research evaluations are often embedded within national evaluation systems. Generally, a national research evaluation system sensitizes universities to routinely collect and monitor the data required for planned assessments. The Research Evaluation Framework (REF) of the United Kingdom is the most comprehensive and well-known of these systems. Every six years, discipline-based expert panels assess the quality of university research in terms of three dimensions: outputs, impact and environment (HEFCE 2012). The Netherlands also has a system of research evaluation. Their Standard Evaluation Protocol (SEP) describes the methods and criteria used to assess the quality and societal relevance of publicly funded research, in overlapping six year periods (KNAW 2014). The assessment of the societal relevance of research in the Netherlands involves a set of valorisation indicators. Compilation of a 4D valorisation map for a Dutch university, therefore, would naturally support the requirements of the SEP, which, in theory, means that the data for valorisation mapping should also be more readily available for a university (although in reality this might not be the case).

Zimbabwe has no national system for the evaluation or monitoring of university research. The Research Council of Zimbabwe (RCZ) is the government agency with the closest related function. However, the RCZ is only mandated to guide, direct, promote and co-ordinate research, which it does by aligning research with national development priorities and by facilitating research funding and collaboration (RCZ 2017). The council has no mandate to 
assess the broader impacts of university research. In Zimbabwe, therefore, any attempt to collect data on dissemination and engagement activities would need to be initiated and driven by the universities, if not the faculties and departments themselves. This surely is no straight-forward task to manage, given resource constraints and the diaspora of university graduates and researchers currently outside the country.

\section{ACKNOWLEDGMENT}

This research was funded with support from the Development Research Uptake in Sub-Saharan Africa (DRUSSA) programme. The DRUSSA programme ran from 2011 to 2016 and was funded by the Department for International Development (DFID), which is a United Kingdom government department responsible for administering overseas aid.

\section{REFERENCES}

Benneworth, P. and V. W. Jongbloed. 2010. Who matters to universities? A stakeholder perspective on humanities, arts and social sciences valorisation. Higher Education 59(5): 567-588.

Boshoff, N. 2010. South-South research collaboration of countries in the Southern African Development Community (SADC). Scientometrics 84(2): 481-503.

Boshoff, N. 2014. Types of knowledge in science-based practices. JCOM: Journal of Science Communication 13(3): 1-16. https://jcom.sissa.it/sites/default/files/documents/JCOM_1303_ 2014_A06.pdf (Accessed 12 September 2017).

Boshoff, N. 2017. South African corresponding authors on perceived beneficiaries and the nature of university research. South African Journal of Higher Education 31(3): 46-62.

Chinamasa, E. 2012. Factors affecting lecturer research output in new universities in Zimbabwe. Zimbabwe Journal of Educational Research 24(2): 162-175. http://opendocs.ids.ac.uk/ opendocs/handle/123456789/6197 (Accessed 8 June 2017).

Cross, E. 2016. The economic and political crisis in Zimbabwe. http://www.thezimbabwean.co/ 2016/07/the-economic-and-political-crisis-in-zimbabwe/ (Accessed 8 June 2017).

Department for International Development. 2016. Research uptake - A guide for DFID-funded research programmes. https://www.gov.uk/government/uploads/system/uploads/attachment_data/file/ 514977/Research_uptake_guidance.pdf (Accessed 8 June 2017).

Development Research Uptake in Sub-Saharan Africa. 2016. Programme completion report. October 2012 - September 2016. https://www.acu.ac.uk/focus-areas/research-management-uptake/drussalearning-resource (Accessed 8 June 2017).

DFID see Department for International Development.

DRUSSA see Development Research Uptake in Sub-Saharan Africa.

ECV see Erasmus Centre for Valorisation.

Enders, J. and A. E. de Weert. 2009. The changing face of academic life: Analytical and comparative perspectives. London: Palgrave Macmillan.

Erasmus Centre for Valorisation. 2013. From knowledge to impact. Rotterdam: ECV. https://www.eur.nl/ fileadmin/ASSETS/ECV/documenten/Summary_policy_report_Making_the_Most_of_Capital_. pdf (Accessed 8 June 2017).

Grobbelaar, S. S. and T. Harber. 2016. Towards the institutionalization of research uptake management in sub-Saharan African universities. Journal of Higher Education in Africa 14(1): 155-183. 
HEFCE see Higher Education Funding Council for England.

Higher Education Funding Council for England. 2012. Assessment framework and guidance on submissions. REF2014 Research Excellence Framework. http://www.ref.ac.uk/media/ref/content/ pub/assessmentframeworkandguidanceonsubmissions/GOS\%20including\%20addendum.pdf (Accessed 14 July 2017).

Hirsch, J. E. 2005. An index to quantify an individual's scientific output. Proceedings of the National Academy of Sciences 102(46): 16569-16572.

Hladchenko, M. 2016. Knowledge valorisation: A route of knowledge that ends in surplus value (an example of the Netherlands). International Journal of Educational Management 30(5): 668-678.

KNAW see Koninklijke Nederlandse Akademie van Wetenschappen.

Koninklijke Nederlandse Akademie van Wetenschappen. 2014. Standard Evaluation Protocol 20152021: Protocol for research assessments in the Netherlands. https://www.knaw.nl/nl/ actueel/publicaties/standard-evaluation-protocol-2015-2021 (Accessed 14 July 2017).

Mawoyo, I. 2012. Zimbabwe. In A profile of higher education in southern Africa. Volume 2. National perspectives, ed. P. Kotecha. Johannesburg: Southern African Regional Universities Association.

Mouton, J., N. Boshoff, L. de Waal, S. Esau, B. Imbayarwo, M. Ritter and D. van Niekerk. 2008. The state of public science in the SADC region. In Towards a common future: Higher education in the $S A D C$ region. Research findings from four SARUA studies, ed. P. Kotecha. Johannesburg: Southern African Regional Universities Association.

National University of Science and Technology. 2007. Intellectual property policy. Bulawayo: NUST.

National University of Science and Technology. 2011a. NUST research board procedures and guidelines for applicants. Bulawayo: NUST.

National University of Science and Technology. 2011b. NUST yearbook 2011/2012. Bulawayo: NUST.

National University of Science and Technology. 2013 NUST draft research policy. Bulawayo: NUST.

National University of Science and Technology. 2016a. Faculty of applied sciences. http://www.nust.ac.zw/fas/ (accessed 20 May 2016)

National University of Science and Technology. 2016b. RIO-SET. http://www.nust.ac.zw/ rioset2016/about.html (Accessed 20 May 2016).

National University of Science and Technology. 2016c. Vice chancellor's 2015 annual report. Bulawayo: NUST.

National University of Science and Technology. 2017a. About NUST vision and mission statement. http://www.nust.ac.zw/index.php/about-nust/vision-and-mission-statement (Accessed 8 June 2017).

National University of Science and Technology. 2017b. Applied biology and biochemistry. http://www.nust.ac.zw/sbb/mission_vision.php (Accessed 5 October 2016 and 6 June 2017).

National University of Science and Technology. 2017c. Applied chemistry. www.nust.ac.zw/sch/ mission_vision.php (Accessed 5 October 2016 and 6 June 2017).

National University of Science and Technology. 2017d. Applied mathematics. www.nust.ac.zw/sma/ mission_vision.php (Accessed 5 October 2016 and 6 June 2017).

National University of Science and Technology. 2017e. Applied physics. www.nust.ac.zw/sph/mission _vision.php (Accessed 5 October 2016 and 6 June 2017).

National University of Science and Technology. 2017f. Computer science. www.nust.ac.zw/ scs/mission_vision.php (Accessed 5 October 2016 and 6 June 2017).

National University of Science and Technology. 2017g. Environmental science and health. www.nust.ac.zw/esh/mission_vision.php (Accessed 5 October 2016 and 6 June 2017).

National University of Science and Technology. 2017h. Forest resources and wildlife management. www.nust.ac.zw/efw/mission_vision.php (Accessed 5 October 2016 and 6 June 2017). 
National University of Science and Technology. 2017i. Sports science and coaching. www.nust.ac.zw/ ssc/mission_vision.php (Accessed 5 October 2016 and 6 June 2017).

National University of Science and Technology. 2017j. Statistics and operations research. www.nust.ac.zw/sors/mission_vision.php (Accessed 5 October 2016 and 6 June 2017).

Ndlovu, H., M. Joubert and N. Boshoff. 2016. Public science communication in Africa: Views and practices of academics at the National University of Science and Technology in Zimbabwe. Journal of Science Communication 15(6): 1-29.

NUST see National University of Science and Technology.

OPC see Office of the President and Cabinet.

Office of the President and Cabinet. 2017. Office of the president and cabinet (O.P.C.). http://www.theopc.gov.zw/ (Accessed 3 July 2017).

Pasipamire, N. 2015. Research support by subject librarians in selected state universities in Zimbabwe: Accommodating new trends. In The quest for deeper meaning of research support, ed. R. Reggie, A. Adam, G. Johnson, C. Miller and J. Pietersen. Cape Town: University of Cape Town Libraries. openbooks.uct.ac.za/arl/index.php/uctlibraries/catalog/download/17/15/139-3 (Accessed 8 June 2017).

RCZ see Research Council of Zimbabwe.

Research Council of Zimbabwe. 2017. About RCZ. http://www.rcz.ac.zw/about/ (Accessed 14 July 2017).

Scientific Industrial Research and Development Centre. 2003. An analysis of the cause and effect of brain drain in Zimbabwe. Harare: SIRDC.

SIRDC see Scientific Industrial Research and Development Centre.

Spaapen, J. and L. van Drooge. 2011. Introducing “productive interactions” in social impact assessment. Research Evaluation 20(3): 211-218.

University of Amsterdam. 2014. Valorisation at the University of Amsterdam. Amsterdam: UvA.

Upton, S., P. Vallance and J. Goddard. 2014. From outcomes to process: Evidence for a new approach to research impact assessment. Research Evaluation 23(4): 352-365.

UvA see University of Amsterdam.

Van Drooge, L., R. Vandeberg, F. Zuijdam, B. Mostert, B. van der Meulen and E. Bruins. 2013. Valuable: Indicators for valorisation. The Hague and Utrecht: Rathenau Institute and Technology Foundation STW.

Van Drooge, L. and S. de Jong. 2015. Valorisation: Researchers do more than they realize. E-publication with examples and guidelines for knowledge transfer. The Hague: Rathenau Institute. 